\section{ABERDEEN DENTAL SCHOOL OPENS}

Scotland's newest dental school was officially opened recently by First Minister Alex Salmond and Public Health Minister Shona Robison. The $£ 17.7$ million Aberdeen Dental School, which has been treating NHS patients since June, will produce 20 fully-qualified dentists every year and will increase the number of people entering the profession in Scotland.

The project was jointly funded by the Scottish Government and NHS Grampian, and facilities include clinical areas supporting student learning in integrated oral care, restorative dentistry, paediatric dentistry, dental accident and emergency, oral surgery, oral medicine and orthodontics. There are also units for sedation, special care dentistry and dental imaging, consultant services in restorative dentistry and orthodontics, dental and student laboratories, a clinical skills facility, decontamination suite and IT centre.

Mr Salmond said, 'Aberdeen Dental School will deliver a significant increase in the number of NHS dentists, and our incentives will help ensure that they stay here and continue to practise in areas such as the North East, where there is most need.'

\section{HTM 01-05 EVIDENCE UNDER BDA SCRUTINY}

The BDA has now received from the Chief Dental Officer (CDO) for England, Barry Cockcroft, the grading of the research which is quoted as the evidence-base for the decontamination document HTM 01-05.

The grading denotes the scientific robustness of the research and documents quoted and is currently being closely scrutinised by the BDA's Health and Science Committee. The BDA's recent request for NICE to examine HTM 01-05 in order to report on its scientific provenance and cost-benefit was denied by the CDO as being unnecessary.

\section{EXHIBITION CELEBRATES LIFE OF DENTAL PIONEER AND FIRST BDA PRESIDENT}

The British Dental Association (BDA) Museum is celebrating the life of Victorian dental pioneer Sir John Tomes with an exhibition focusing on his work and achievements. The exhibition features a number of Tomes' inventions including his patients' chair and hand instruments, including forceps the design of which is acknowledged as the forerunner of those used today.

Other unique items featured include his work room book containing drawings of sections of teeth and bone seen under a microscope, the letter from the Royal Society awarding him his Fellowship and his cuttings book, which includes the telegraph message informing him that the 1878 Dentist's Act - the legislation that confined the use of the term 'dentist' to qualified or experienced people - had been passed.

Tomes was a clinical, technical and political pioneer in dentistry. As well as being the first registered dentist and the first President of the BDA, he also holds the distinction of being the first dentist to be elected a Fellow of the Royal Society on the basis of his dental research.

Peter Ward, Chief Executive of the BDA, said, 'It is the BDA's 130th birthday this year, so it is particularly fitting that we are celebrating the life of Sir John Tomes, our first President, with this

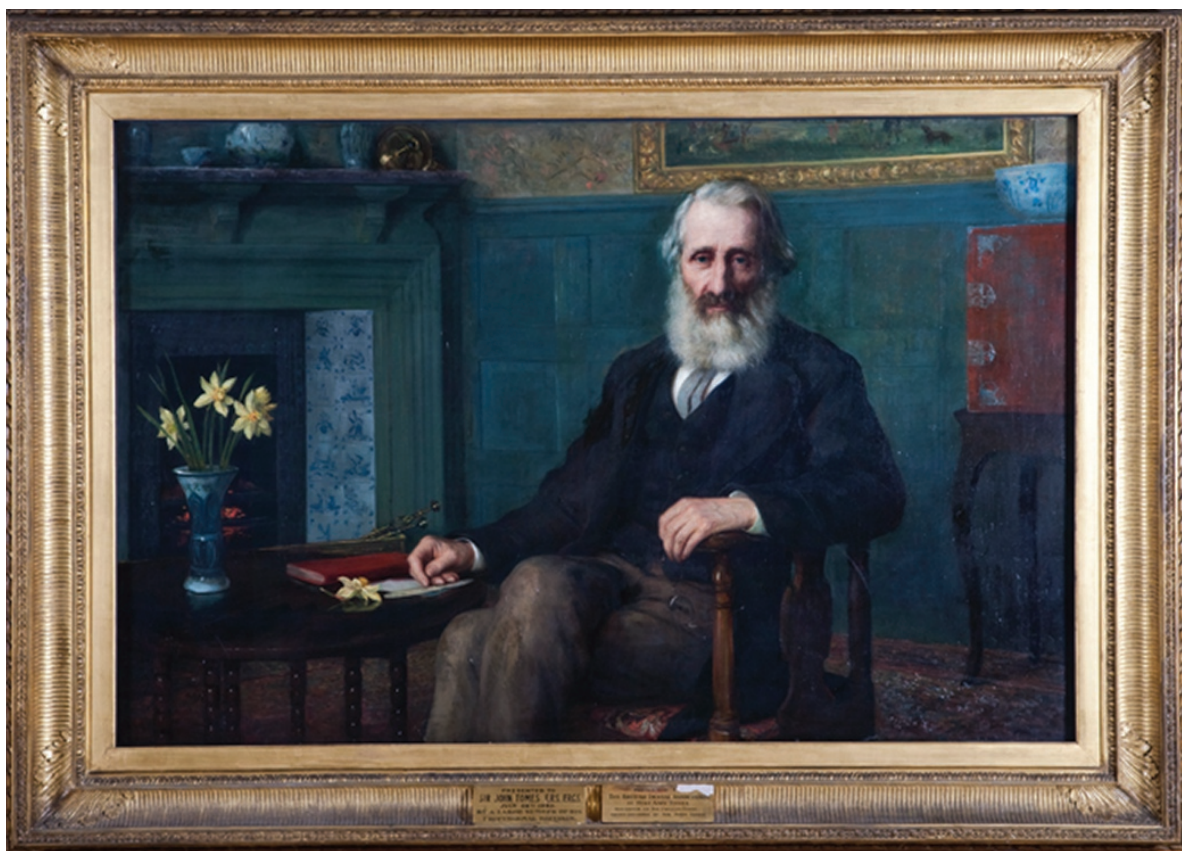

Tomes portrait by Carlile Henry Hayes Macartney, 1880. The portrait was commissioned by the Dental Reform Committee and shows Tomes in his office amongst his favourite belongings. The picture was exhibited at the Royal Academy in 1882

exhibition. His achievements and innovations have had a profound influence on the way dentistry is organised, regulated and practised today, and every dentist owes him a huge debt of thanks.'

The exhibition can be viewed at the British Dental Association until 4 March. It is open during normal museum opening hours (Tuesdays and Thursdays 1pm$4 \mathrm{pm}$ ), but visitors are welcome at other times by appointment. Admission is free.

The exhibition will then travel to the East Surrey Museum, Caterham, from 13 March 5 June, and to the Hunterian Museum at the Royal College of
Surgeons of England, London from 22 June to 25 September.

The exhibition is being supported by the Royal Society, the UK's national academy of science, of which Sir John Tomes was a Fellow. Between November 2009 and November 2010, the Royal Society is celebrating its 350th anniversary with a series of events, exhibitions and publications to increase the profile of science and engagement with science among the public. This exhibition is part of the Society's 'Local Heroes' programme, a nationwide celebration of Royal Society Fellows at 50 museums and galleries. 